\title{
PENGARUH POSISI PEMBAKARAN DALAM TUNGKU TERHADAP DAYA LEKAT (BOND SHEAR) BATA MERAH PEJAL
}

\author{
Muhamad Nur Rokib, Irza Ahmad, Dadang Suyadi S
}

\begin{abstract}
In it's made, red brick cand be made by the sample way and using modern machine too. But, a lot of red brick made by made home industry so, the quality between the region is not same each other. This research aim to examine the difference of red brick bond shear caused by the difference of burning position in the fire place. The research had been done in the material laboratory in University Of Indonesia, Depok. The reaserch schedule is from March to May 2002. This research method is using experimental method through material test in laboratory with thee different behaviors, that is for the fist group, the pair of the red solid brick is taken from the top of the fire place, second group, the pair of solid brick is taken from the midle of the fire place. The third group, the pair of red solid brick is taken from the bottom of the fire place. These three groups using 1PC : 4 PS composition each group is using is samples for horizontal friction test of the red solid brick pair from this research date, we can get the bond shear rate from the pair of red solid brick on the top of fire place is 0,486 $\mathrm{MPa}$, the bond shear rate from the pair of red solid brick in the midle of fire place is $1,088 \mathrm{MPa}$, the bond shear rate from the pair of red solid brick atau the bottom of fire place is 1,333 MPa. The hipotesis test by using one way varians analiysist, we can get $F_{\text {cound }}=42,6$ in sigificant level $(\alpha=0,01)$ and we can get $F_{\text {table }}=5,15$, because $F_{\text {cound }}>F_{\text {table }}$, so Ho is refused. The result of this research, we can find the difference of red solid brick bond shear caused by the difference position burning in the fire place.
\end{abstract}

Keywords: red brick, burning position

\begin{tabular}{|lrr|}
\hline Muhamad Nur Rokib & Ir. Irza Ahmad, MT & Drs. Dadang Suyad i, MPd \\
Alumni Jurusan Teknik Sipil & Staff Pengajar Jurusan Teknik Sipil & Staff Pengajar Jurusan Teknik Sipil \\
Fakultas Teknik & Fakultas Teknik & Fakultas Teknik \\
Universitas Negeri Jakarta, 13220 & Universitas Negeri Jakarta, 13220 & Universitas Negeri Jakarta, 13220 \\
\hline
\end{tabular}

\section{PENDAHULUAN}

Perbandingan Biaya Atara Penggunaan Kuda - Kuda Baja Dengan Kuda - Kuda

Kayu Pada Rumah Tinggal,

Ir. Irika Widiasanti, Fonita,S.Pd 
Bata merah dalam pembuatannya dapat dilakukan secara sederhana dan dapat pula memakai mesinmesin modern. Tetapi banyak industri bata merah dibuat oleh industri kecil, sehingga kualitas yang dihasilkan antara daerah yang satu dengan yang lain tidak sama.

Bata merah merupakan batu batuan yang berasal dari tanah liat yang dalam lekat dicetak, dijemur beberapa hari sesuai dengan aturan lalu dibakar sampai matang, sehingga tidak hancur apabila direndam dalam air.

Pada Industri bata merah, tahap-tahap proses pembuatan mulai dari pengambilan bahan baku yang cocok untuk di buat bata merah, pembentukan atau pencetakan, pengeringan, pembakaran.

Industri bata merah sebagai salah satu industri kecil yang banyak menggunakan bahan bakar kayu karet sebagai sumber energi alternatif pada tungku pembakarannya.

Bata merah yang baik mutunya sangat di pengaruhi oleh temperatur pembakaran bata merah konvensional temperatur pembakaran adalah $1200^{\circ} \mathrm{C}$ pada kantong api. Susunan bata merah pada tungku lapisan atas mendapatkan temperatur $600^{\circ} \mathrm{C}$, tengah $850^{\circ} \mathrm{C}$ dan paling bawah $900^{\circ} \mathrm{C}$. temperatur ideal hanya di peroleh bata merah yang berada pada lapisan tengah.

Pembakaran dari bata merah antara susunan bata pada tungku lapisan atas, tengah, dan bawah berbeda suhunya. Apabila pasangan dinding bata merah mendapatkan gaya lateral, yang disebabkan oleh gempa dan angin maka retakan tidak terjadi, bila bata merah melekat dengan baik dan sebaliknya apabila ada retakan, maka bata merah tidak melekat dengan sempurna. Dinding bata merah ada sebagai struktur dan ada sebagai partisi. Berdasar perbedaan suhu, susunan bata merah dalam tungku dan asumsi sebagian masyarakat bahwa bata merah sama, walaupun susunan bata merah dalam tungku berbeda, dan bata merah tidak hanya sebagai partisi.

Daya lekat adalah kemampuan menempel dengan benar-benar sehingga tidak mudah lepas. Daya lekat atau disebut juga bond shear dipengaruhi oleh adukan ataupun oleh bata merah tersebut. Apabila daya lekatnya baik maka kuat geser bata merah tersebut pada waktu menerima beban horizontal tidak mudah lepas.

Bond shear merupakan proses pengujian kemampun pasangan bata merah dalam menerima beban, sehingga nantinya diketahui nilai geseran. Dalam Pengujian digunakan uji kuat geser harizontal bata merah struktur. Shear merupakan bentuk yang dominan dari kegagalan yang diteliti dalam banyak gedung-gedung yang menggunakan bata merah dan difokuskan pada beban lateral terhadap gempa bumi, angin, atau penyebab yang lain. Beban lateral dapat menyebabkan keretakan diagonal dan 
bentuk kegagalan horizontal pada titik tekan. Pengetahuan dari kelakuan adalah penting jika bentuk analisa cukup untuk dikembangkan yang dalam kelakuan dari dinding. Kelakuan Shear bata merah yang telah dibatasi pada ketentuan kekuatan puncak shear dan faktor-faktor yang mempengaruhinya, faktor-faktor yang mempengaruhi ketahanan puncak shear antara lain tipe adukan, air adukan, perbandingan semen, struktur permukaan bata merah, dan hasil dari pembakaran.

Semen menjadi perekat yang tercampur dengan air akan menjadi keras dan bertambah kekuatannya menurut umurnya. Semen dapat digunakan terutama dalam pembangunan sebagai adukan (semen, pasir dan air atau semen, kapur, pasir dan air). Antar bata merah itu terdapat spesi mengadakan lekatan sehingga nantinya mengasilkan daya lekat.

Bata merah adalah unsur bangunan yang digunakan untuk pembuatan bagian konstruksi, dengan rupa-rupa batuan-batuan yang dibuat dari tanah liat dengan ataupun tanpa campuran bahan lain. Berbentuk balok persegi panjang dan dibakar pada suhu yang tinggi mengeras, sehingga tidak dapat hancur bila direndam air.

Bata merah bahan dasarnya berupa tanah liat atau lempung. Penggunaan air dalam pembuatan bata merah berfungsi agar lempung mempunyai sifat plastis agar mudah dalam pembentukan. Setelah lempung ditambahkan air akan menjadi plastis sehingga memungkinkan lempung tersebut dapat dibentuk sesuai dengan yang diinginkan / direncanakan.

Mula-mula bahan mentah berupa tanah liat yang telah disiapkan kemudian dicampur sambil diaduk dan ditekan agar merata. Didalam uraian proses pembuatan bata merah secara garis besar melalui tahapan-tahapan yang perlu diperhatikan agar kesulitan yang timbul dapat diatasi sehingga diharapkan kualitas / mutu produksi yang lebih baik.

Persiapan bahan mentah bertujuan untuk menghasilkan massa siap pakai yang tentunya mempunyai kecocokan sebagai bahan baku untuk produk bata merah.

Penyusunannya menyerupai alur tikus dengan empat unit bata merah setiap kelompok, sehingga lidah api mampu mencapai keseluruhan bata merah yang dibakar.

Pada pembakaran selama kurang lebih 2 hari $(2 \times 24$ Jam) dan pembongkaran dilakukan setelah api dingin. Satu siklus pembakaran membutuhkan waktu sekitar 7 hari, sejak menyusun bata merah sampai dingin hingga dapat dibongkar dari tungku pembakaran. Satu dapur pembakaran 
mempunyai kapasitas 40.000 - 80.000 unit setiap kali pembakaran. Bata merah pejal harus memenuhi syarat mutu menurut Standar Nasional Indonesia Nomer 15-2094-2000.

Adanya persepsi dalam masyarakat bahwa bata merah pejal dengan sistem pembakaran konvensional akan menghasilkan mutu bata yang sama, baik yang dekat dengan panas pembakaran maupun yang jauh. Pada hal susunan bata merah pejal dalam tungku pembakaran berbeda, dari hal ini maka peneliti ingin membuktikan hal tersebut.

Spesi merupakan campuran agregat halus dengan semen dan air yang dipakai untuk melekatkan antar bata merah. Spesi yang digunakan dengan perbandingan campuran 1PC : 4PS dan termasuk kelas pasangan bata nomer satu yaitu untuk diding struktural yang terpengaruh atau tidak terpengaruh oleh perubahan cuaca.

Untuk mengetahui daya lekat (bond shear) bata merah pejal karena perbedaan posisi pembakaran dalam tungku, untuk mengetahui daya lekat dapat juga digunakan sistim pre kompresi dan dapat dipergunakan uji kuat geser (tekan) horisontal pasangan bata merah, karena mengacu pada SNI maka dalam penelitian ini menggunakan uji geser (tekan) horisontal. Dari uji itu akan mendapatkan nilai yang berbeda antara susunan pembakaran yang berada diatas, tengah, dan bawah. Diambil nilai ratarata masing-masing susunan dari atas, tengah dan bawah posisi pembakaran dalam tungku.

Apakah ada perbedaan signifikan dalam daya lekat (bond shear) bata merah pejal karena perbedaan posisi pembakaran dalam tungku.

\section{(i) Tujuan Operasional Penelitian}

Tujuan penelitian ini adalah untuk mengetahui perbedaan daya lekat (bond shear) bata merah pejal karena perbedaan posisi pembakaran dalam tungku.

\section{(ii) Tempat dan Waktu Penelitian}

Penelitian dilaksanakan dilaboratorium bahan Teknik sipil Universitas Indonesia Kampus Baru UI Depok.

Adapun Penelitian akan dilaksanakan Bulan Januari 2002 sampai dengan bulan Mei 2002.

\section{(iii) Teknik Pengambilan Sempel}

Populasi dalam penelitian adalah bata merah yang dihasilkan dari hasil pembakaran industri bata merah pejal daerah Cikarang yang telah dipasang spesi dengan tiga bata, dari masing-masing posisi pembakaran dalam tungku atas, tengah dan bawah adalah 20 buah. 
Sampel yang diambil dalam penelitian ini yaitu bata merah pejal yang telah diberi spesi dan diambil berdasarkan posisi pembakaran bata merah pejal pada tungku atas, tengah, dan bawah, sampel masing-masing diambil sebanyak 15 buah. Benda uji melalui penomoran setiap anggota. Sampel dipilih dengan nomor random.

\section{(iv) Teknik Pengumpulan Data}

Teknik pengumpulan data dengan mengumpulkan data penelitian yang diambil dari data kuat geser bata merah pejal. Alat yang digunakan adalah seperangkat alat tekan standar dan LVDT (linier Variable Deformation Tranducer), beserta daftar isian yang dipergunakan untuk mencatat hasil-hasil tes dari masing-masing benda uji.

\section{(v) Teknik Analisa data}

Analisa Penelitian yang dipergunakan menggunakan uji Anava (Analisis Varians) untuk mengetahui perbedaan daya lekat (bond Shear) bata merah pejal karena perbedaan posisi pembakaran dalam tungku. Dan sebelumnya digunakan uji normalitas dan uji homogenitas.

\section{Prosedur Pelaksanaan Penelitian}

Benda uji bata merah pejal dibedakan yang berada di atas posisi pembakaran dalam tungku, dengan yang berada di tengah posisi pembakaran dalam tungku dan yang di bawah posisi pembakaran dalam tungku. Untuk mengetahui daya lekat (bond shear) bata merah pejal salah satunya digunakan uji kuat geser Horizontal.

Cara ujinya meliputi :

1. Persiapan benda uji

Siapkan benda uji sebagai berikut :

a. Rendam bata merah pejal sampai jenuh bagian dalam dan kering permukaan.

b. Siapkan adukan.

2. Pembuatan benda uji

Buat benda uji sebagai berikut :

a. Buat benda uji dengan ketentuan ukuran, untuk pengujian kuat geser horizontal seperti gambar 1 dan gambar 2 .

\section{Perbandingan Biaya Atara Penggunaan Kuda - Kuda Baja Dengan Kuda - Kuda Kayu Pada Rumah Tinggal, Ir. Irika Widiasanti, Fonita, S.Pd}


b. Kaping permukaan atas dan bawah benda uji.

c. Buat nomor atau kode dan tanggal pembuatan benda uji.

d. Jaga kelembaban benda uji, dengan suhu kamar sampai waktu pengujian, dengan cara antara lain menutupi dengan karung basah.
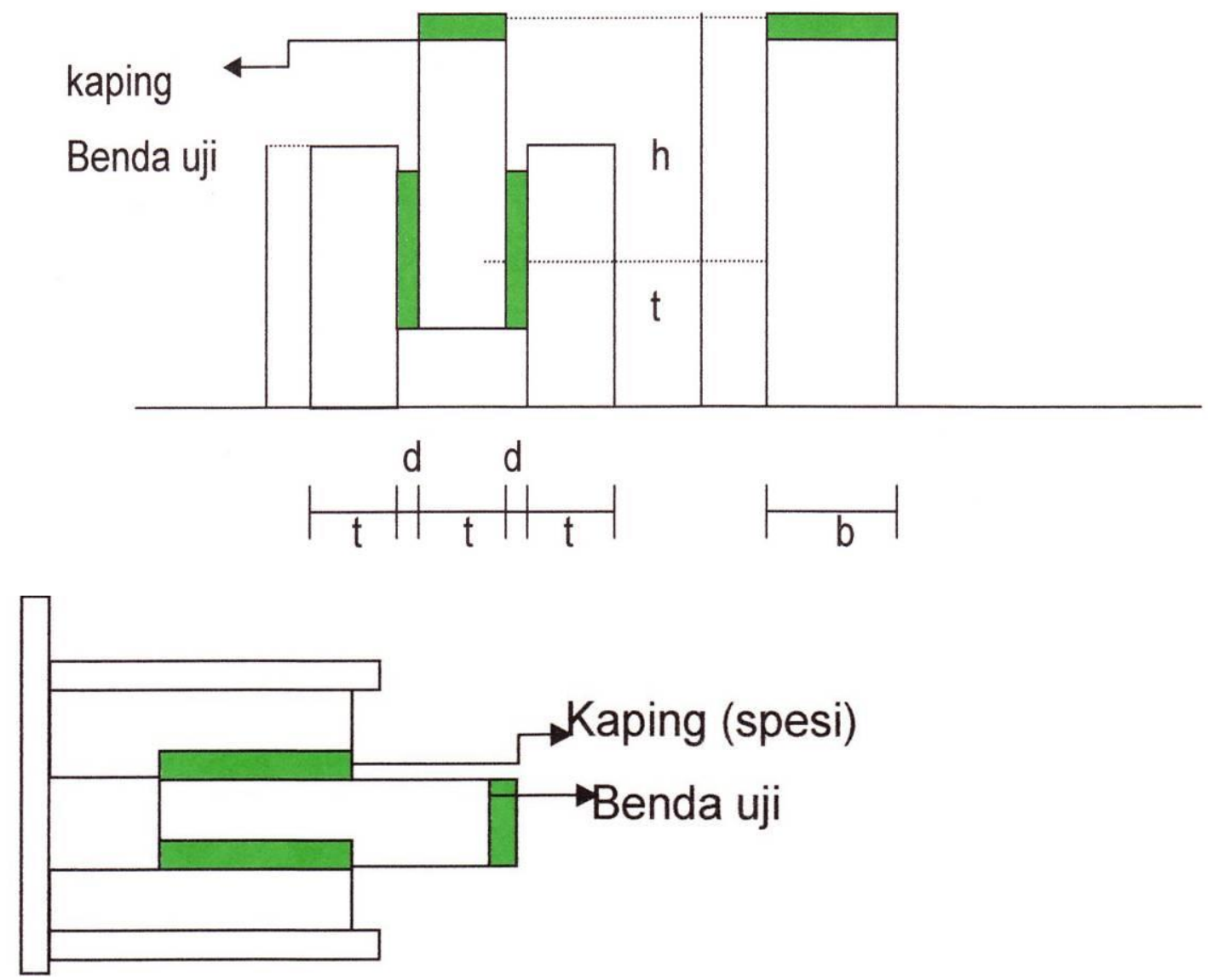

Gambar 1. sketsa cara pembuatan benda uji

Keterangan :

I = panjang bata;

$b=$ lebar bata;

$\mathrm{t}=$ tebal bata;

$d$ = tebal spesi;

3. Pelaksanaan pengujian

Pelaksanaan pengujian Kuat Geser Horizontal dilakukan sebagai berikut : 
a. Ukuran lebar bata dan panjang bidang geser dengan menggunakan roll meter, catat pada formulir pengujian.

b. Timbang berat uji (W) dan alat bantu (W) dan pada formulir pengujian.

C. Hidupkan mesin pada awal pengujian selama 15 menit.

d. Letakkan benda uji sesuai dengan sentris terhadap alat pembeban, dan jepit pada kedua sisinya untuk menguji kuat geser horizontal .

e. Atur jarum penunjuk beban pada posisi nol.

f. Lakukan pembebanan dengan kecepatan konstan merata dan dapat diatur, sehingga gerakan pembebanan antara $150 \mathrm{~N} / \mathrm{mm} /$ menit sampai dengan $210 \mathrm{~N} / \mathrm{mm} / \mathrm{menit}$.

g. Catat nilai beban hancur pada formulir pengujian.

4. Perhitungan kuat geser

Perhitungan kuat geser sebagai berikut :

a. Hitung kuat geser horizontal sesuai dengan rumus dan catat nilai hasil perhitungan dalam formulir pengujian.

$\mathrm{Fvh}=\frac{\mathrm{Pu}+\mathrm{W}}{2\left(\mathrm{bxh}^{\prime}\right)} \quad(\mathrm{MPa})$

Fvh : Kuat geser horizontal dinding pasangan bata merah, dalam MPa.

Pu : Beban uji maksimum, dalam $\mathrm{N}$.

b : Lebar bata, dalam $\mathrm{mm}$.

h. : Panjang bidang geser dalam $\mathrm{mm}$.

w : Massa alat bantu, dalam N.

b. Catat nilai hasil perhitungan dalam formulir pengujian.

\section{Deskripsi Data}

Berdasarkan hasil pengujian nilai Bond Shear bata merah pejal yang berdasarkan pada perbedaan posisi pembakaran dalam tungku diperoleh data pada tabel 1. 
Tabel 1. Nilai Bond Shear Bata Merah Pejal Pada Bagian Atas Tungku, Tengah Tungku Dan Bawah Tungku Pembakaran

\begin{tabular}{|c|c|c|c|}
\hline \multirow{2}{*}{ Nomor } & \multicolumn{3}{|c|}{ Nilai (Bond Shear) (MPa) } \\
\cline { 2 - 4 } & Bagian atas tungku & Bagian bawah tungku & Bagian bawah tungku \\
\hline 1 & 0,16 & 0,87 & 0,81 \\
\hline 2 & 0,20 & 0,91 & 0,86 \\
\hline 3 & 0,29 & 0,91 & 0,87 \\
\hline 4 & 0,36 & 1,08 & 0,87 \\
\hline \multirow{2}{*yyy}{} & & Nilai (Bond Shear) (MPa) \\
\cline { 2 - 4 } & Bagian atas tungku & Bagian atas tungku & Bagian atas tungku \\
\hline 5 & 0,36 & 1,09 & 0,96 \\
\hline 6 & 0,39 & 1,19 & 1,02 \\
\hline 7 & 0,42 & 1,21 & 1,03 \\
\hline 8 & 0,46 & 1,36 & 1,05 \\
\hline 9 & 0,49 & 1,37 & 1,09 \\
\hline 10 & 0,56 & 1,45 & 1,12 \\
\hline 11 & 0,56 & 1,48 & 1,21 \\
\hline 12 & 0,62 & 1,63 & 1,23 \\
\hline 13 & 0,70 & 1,79 & 1,30 \\
\hline 14 & 0,83 & 1,81 & 1,33 \\
\hline 15 & 0,89 & & \\
\hline & & & \\
\hline
\end{tabular}

\section{KESIMPULAN}

Kesimpulan yang dapat ditarik dari hipotesis yang telah di uji adalah sebagai berikut :

1. Terdapat perbedaan yang signifikan dalam daya lekat (bond shear) bata merah pejal karena perbedaan posisi pembakaran. Pembakaran bata merah pejal dengan sistim konvensional antara susunan atas, tengah dan bawah tungku pembakaran dengan mortal 1 Pc : 4 PS. Jadi dari ketiga kelompok perlakuan memberikan hasil secara nyata perbandingan satu sama lain.

2. Nilai bond shear rata-rata pasangan bata merah pejal pada susunan atas tungku pembakaran secara konvensional adalah $0,486 \mathrm{MPa}$, pasangan bata merah pejal pada susunan tengah 
tungku pembakaran secara konvensional adalah 1,333 MPa, pasangan bata merah pejal pada susunan bawah tungku pembakaran secara konvensional adalah 1,088 MPa.

3. Bata merah pejal yang yang berada di susunan tengah mempunyai daya lekat (bond shear) yang optimum karena temperatur yang ideal, tidak terlalu panas dan tidak kurang suhunya.

\section{DAFTAR PUSTAKA}

Atkinson R.H. Journal of Struktur Engginering, Vol 115,1989, ASCE, ISSN, 1989.

Balai Penelitian Bahan. Petunjuk Teknis Proses Pembuatan Bata Merah Pejal_: Balai Penelitian Bahan Dinas Perindustrian DKI Jakarta, 1978.

Departemen Peridustrian. Pengembangan Pembuatan Batu Bata Dalam Rangka Standarisasi, Sulawesi Uatara, Manado : Departemen Perindustrian, 1989.

Direktorat Penyelidikan Masalah Bangunan. Peraturan Beton Bertulang Indonesia 1971 N I, Yayasan Dana Normalisasi Indonesia, 1977.

Frick, Heinz. IImu Konstruksi Bangunan I, Yogyakarta : Yayasan Kanisus, 1980.

Gaylord. Structural Engginering Hand book "Soil Physics" Hungary : Elseiver Sciebtific Publising Company, 1974.

Gunawan, Rudy. Pengantar Ilmu Bangunan, Yogyakarta : Kanisus, 1978.

Laboratorium Struktur dan Bahan Teknik Sipil. Pedoman Pelaksanaan Praktikum, Bandung : Fakultas Teknik ITB, 1995.

Nawy, Edward G. Beton Bertulang Suatu Pendekatan Dasar, Bandung PT Eresco, 1990.

Pijl, A. Ringkasan Ilmu Bangunan, Terjemahan Hendarsih H, Jakarta : Erlangga, 1983.

Razak, RA. Industri Keramik, Jakarta : Pekerjaan Umum Balai Pustaka, 1981.

Supribadi, IK . IImu Bangunan Gedung Seri A, Bandung Amico, 1986.

Soraya, et antara lain . Aspek Tekno Ekonomi Batu Bata Sebagai Energi Alternatif Pada Industri Pembakaran Batu Bara, Universitas Syah Kuala Banda Aceh, 1998.

SNI 03-4166-1996. Metode Pengujian Kuat Geser Dinding Pasangan Bata Merah Di Laboratorium, Dewan Standarisasi Nasional, 1996.

SNI 15-2094-2000. Bata Merah Pejal Untuk Pasangan Dinding, Dewan Standarisasi Nasional, 2000.

S. Fredick, Merrit .Standart Hand Book For Civil Enggenering, New York : Mc Graw Hill Book Company, 1976. 
Tim Penyusun Kamus Besar Pembinaan dan Pengembangan Bahasa. Kamus Besar Bahasa Indonesia, Balai Pustaka, 1989.

Universitas Negeri Jakarta, Pedoman Kegiatan Akademik Universitas Negeri Jakarta, UNJ 2001.

Wesly, LD. Mekanika Tanah, Jakarta : Badan Penerbit Pekerjaan Umum, 1972.

Wansadinata, Wiratman. Peraturan Beton Bertulang Indonesia, Cetakan ke 7, Jakarta : Derektorat Jendral Cipta Karya, 1979 